\title{
Mitochondrial aminoacyl-tRNA synthetase disorders: an emerging group of developmental disorders of myelination
}

\author{
Amena Smith Fine ${ }^{1,2^{*}}$, Christina L. Nemeth ${ }^{1,3}$, Miriam L. Kaufman ${ }^{1,3}$ and Ali Fatemi ${ }^{1,3}$
}

\begin{abstract}
Background: The mitochondrial aminoacyl-tRNA synthetase proteins (mt-aaRSs) are a group of nuclear-encoded enzymes that facilitate conjugation of each of the 20 amino acids to its cognate tRNA molecule. Mitochondrial diseases are a large, clinically heterogeneous group of disorders with diverse etiologies, ages of onset, and involved organ systems. Diseases related to mt-aaRS mutations are associated with specific syndromes that affect the central nervous system and produce highly characteristic MRI patterns, prototypically the DARS2, EARS, and AARS2 leukodystrophies, which are caused by mutations in mitochondrial aspartyl-tRNA synthetase, mitochondria glutamate tRNA synthetase, and mitochondrial alanyl-tRNA synthetase, respectively.

Body: The disease patterns emerging for these leukodystrophies are distinct in terms of the age of onset, nature of disease progression, and predominance of involved white matter tracts. In DARS2 and EARS2 disorders, earlier disease onset is typically correlated with more significant brain abnormalities, rapid neurological decline, and greater disability. In AARS2 leukodystrophy cases reported thus far, there is nearly invariable progression to severe disability and atrophy of involved brain regions, often within a decade. Although most mutations are compound heterozygous inherited in an autosomal recessive fashion, homozygous variants are found in each disorder and demonstrate high phenotypic variability. Affected siblings manifest disease on a wide spectrum.

Conclusion: The syndromic nature and selective vulnerability of white matter tracts in these disorders suggests there may be a shared mechanism of mitochondrial dysfunction to target for study. There is evidence that the clinical variability and white matter tract specificity of each mt-aaRS leukodystrophy depend on both canonical and non-canonical effects of the mutations on the process of mitochondrial translation. Furthermore, different sensitivities to the mt-aaRS mutations have been observed based on cell type. Most mutations result in at least partial retention of mt-aaRS enzyme function with varied effects on the mitochondrial respiratory chain complexes. In EARS2 and AARS2 cells, this appears to result in cumulative impairment of respiration. Mt-aaRS mutations may also affect alternative biochemical pathways such as the integrated stress response, a homeostatic program in eukaryotic cells that typically confers cytoprotection, but can lead to cell death when abnormally activated in response to pathologic states. Systematic review of this group of disorders and further exploration of disease mechanisms in disease models and neural cells are warranted.
\end{abstract}

Keywords: Leukodystrophy, Mitochondrial aminoacyl-tRNA synthetases, DARS2, LBSL, EARS2, LTBL AARS2, Ovario-leukodystropy

\footnotetext{
* Correspondence: smithame@kennedykrieger.org

${ }^{1}$ Moser Center for Leukodystrophies at the Kennedy Krieger Institute,

Baltimore, MD 21205, USA

${ }^{2}$ Department of Neurology and Developmental Medicine, Kennedy Krieger

Institute, Baltimore, MD 21205, USA

Full list of author information is available at the end of the article
}

(c) The Author(s). 2019 Open Access This article is distributed under the terms of the Creative Commons Attribution 4.0 International License (http://creativecommons.org/licenses/by/4.0/), which permits unrestricted use, distribution, and reproduction in any medium, provided you give appropriate credit to the original author(s) and the source, provide a link to the Creative Commons license, and indicate if changes were made. The Creative Commons Public Domain Dedication waiver (http://creativecommons.org/publicdomain/zero/1.0/) applies to the data made available in this article, unless otherwise stated. 


\section{Background}

Mitochondria are comprised of products encoded by two genomes, nuclear and mitochondrial, totaling roughly 1500 genes $[1,2]$. Aminoacyl-tRNA synthetase proteins (aaRSs) are a group of nuclear-encoded enzymes that ensure correct translation of the genetic code by conjugating each of the 20 amino acids to their cognate tRNA molecule [3-5]. The cytosolic aaRS enzymes supply aminoacyl-tRNA conjugates for protein translation, and the corresponding mtaaRSs are imported into the mitochondrial matrix to perform their canonical role of charging amino acids to their mitochondrial genome-encoded tRNA molecules (mttRNA) (Fig. 1). Diseases of mitochondria, the powerplants of the cell, are a large and clinically heterogeneous group of disorders, encompassing a wide diversity of etiologies, ages of onset, involved organ systems, and clinical presentations.
Disorders caused by mt-aaRS mutations are generating particular interest among mitochondrial diseases due to their predilection for the central nervous system (CNS) damage $[11,12]$. It is well known that mitochondrial dysfunction preferentially affects high-energy demand tissues, especially the brain, muscle, and heart. Remarkably, nearly all $\mathrm{mt}-$ aaRS mutations result in CNS pathologies, including encephalopathies, Perrault syndrome, and leukodystrophies [5] (Table 1). Three mutations result in rare, well-defined leukodystrophy syndromes, namely, DARS2, caused by mutations in mitochondrial aspartyl-tRNA synthetase; EARS2, caused by mutations in mitochondria glutamate tRNA synthetase; and AARS2, caused by mutations in mitochondrial alanyl-tRNA synthetase. Only three mt-aaRS mutations lead to pathology outside the CNS. A comprehensive, dynamic source has been developed for emerging information

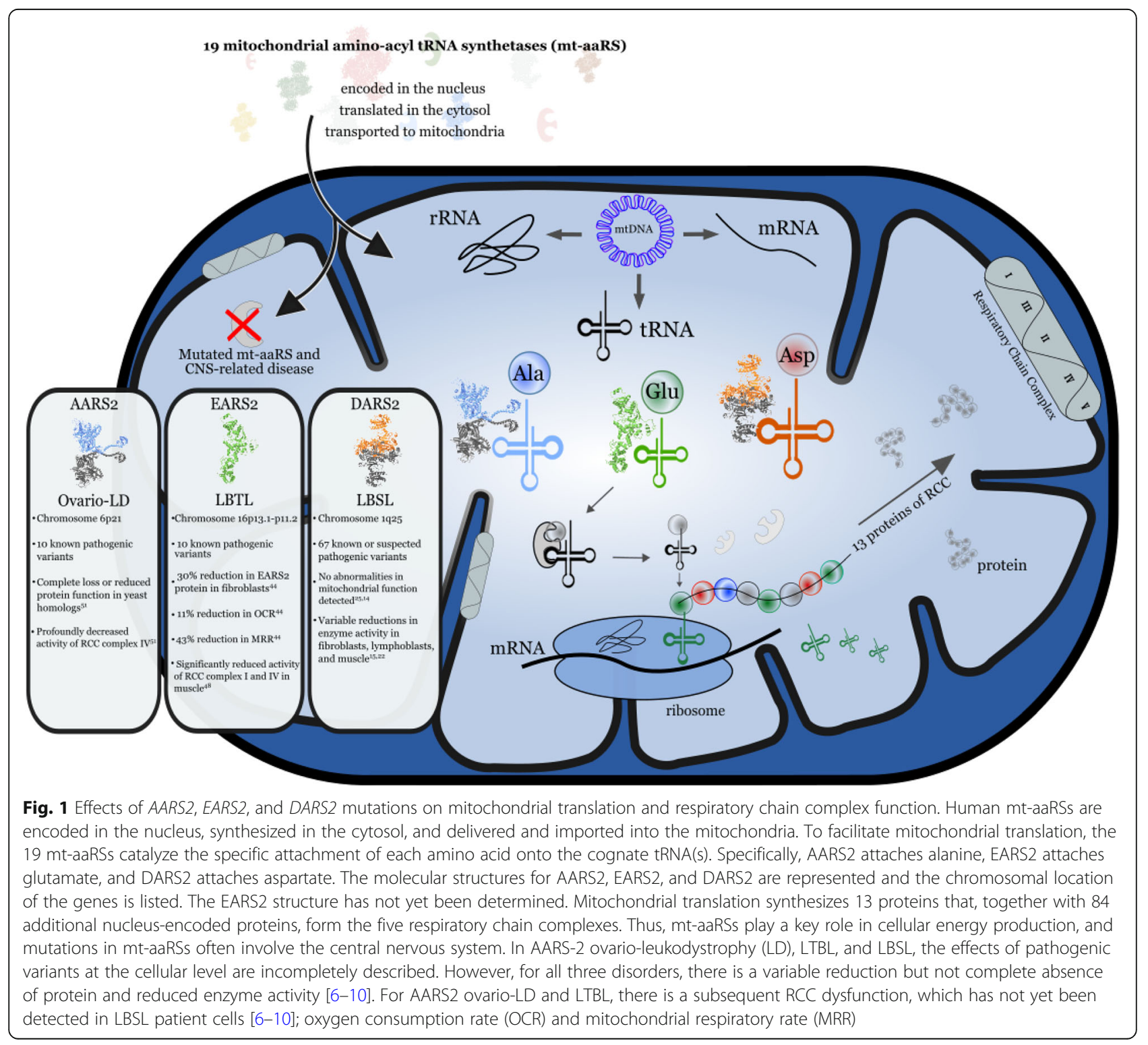


Table 1 Neurological disorders associated with mt-aaRS mutations

\begin{tabular}{|c|c|}
\hline \multicolumn{2}{|c|}{ Leukodystrophy } \\
\hline DARS2 & $\begin{array}{l}\text { Leukoencephalopathy with brainstem and spinal cord } \\
\text { involvement (LBSL) }\end{array}$ \\
\hline EARS2 & $\begin{array}{l}\text { Leukoencephalopathy with thalamus and brainstem } \\
\text { involvement and high lactate (LTBL) }\end{array}$ \\
\hline AARS2 & $\begin{array}{l}\text { Ovario-leukodystrophy; rapid development of motor, } \\
\text { cognitive, and psychiatric dysfunction }\end{array}$ \\
\hline MARS2 & $\begin{array}{l}\text { Skeletal dysplasia, infantile cataracts, congenital neurotrophic } \\
\text { keratitis, orbital myopathy, Leigh syndrome }\end{array}$ \\
\hline \multicolumn{2}{|c|}{ Encephalopathy } \\
\hline RARS & Pontocerebellar hypoplasia type 6 \\
\hline VARS2 & $\begin{array}{l}\text { Mitochondrial encephalomyopathy; psychomotor delay, } \\
\text { epilepsy, intellectual disability, growth hormone deficiency, } \\
\text { hyogonadism }\end{array}$ \\
\hline WARS2 & $\begin{array}{l}\text { Autosomal recessive intellectual disability } \\
\text { Mitochondrial encephalopathy } \\
\text { Infantile-onset Parkinsonism }\end{array}$ \\
\hline TARS2 & $\begin{array}{l}\text { Mitochondrial encephalomyopathy } \\
\text { Axial hypotonia and limb hypertonia, psychomotor delay, } \\
\text { and high levels of blood lactate }\end{array}$ \\
\hline FARS2 & $\begin{array}{l}\text { Alpers sydnome, encephalopathy, epilepsy, lactic acidosis, } \\
\text { spastic paraplegia }\end{array}$ \\
\hline \multicolumn{2}{|c|}{ Perrault syndrome } \\
\hline LARS2 & $\begin{array}{l}\text { Perrault syndrome-sensorineural deafness, ovarian } \\
\text { abnormality, cognitive impairment, areflexia, dysarthia, and } \\
\text { hyporeflexia }\end{array}$ \\
\hline HARS2 & Perrault syndrome \\
\hline PARS2 & $\begin{array}{l}\text { Non-syndromic deafness, Leigh syndrome, intellectual } \\
\text { disability with epilepsy and severe myopathy }\end{array}$ \\
\hline NARS2 & $\begin{array}{l}\text { Non-syndromic deafness, Leigh syndrome, Alpers syndrome, } \\
\text { infantile onset neurodegenerative disorder }\end{array}$ \\
\hline
\end{tabular}

about the mt-aaRS enzymes called MiSynPat (mitochondrial aminoacyl-tRNA synthetases and pathologies). This is a continuously updating database and web server that collects existing and emerging data related to mutations affecting the human mt-aaRSs [5].

Table 1 lists a brief, categorized summary of the neurologic disease phenotypes caused by mt-aaRS mutations.

As diseases associated with mt-aaRS enzymes are being further characterized, each appears to be associated with a very specific clinical syndrome. This phenomenon is best illustrated by the leukodystrophies caused by DARS2 (leukoencephalopathy with brainstem and spinal cord involvement and high lactate, LBSL), EARS2 (leukoencephalopathy with thalamus and brainstem involvement and high lactate, LTBL), and AARS2 mutations (ovario-leukoencephalopathy). Mutations in MARS2 are emerging as a fourth leukodystrophy, although only three cases have been reported thus far, in association with leukoencephalopathy, ataxia, and neurodevelopmental delays $[13,14]$.
The mt-aaRS disorders are inherited in an autosomal recessive fashion, and no de novo cases have been reported in the literature. The mechanisms underlying the specific genetic-clinical correlates are presently unknown. However, the clear syndromic nature of these disorders suggests there may be a shared mechanism that could be targeted for study. There is evidence that neuron-specific differences in the sensitivity to mutations may at least partially explain the selective vulnerability of specific white matter tracts in mt-aaRS leukodystrophies [15-17]. Furthermore, the pathophysiology of the mt-aaRS disorders reflects inconsistent biochemical alterations in the mitochondrial pathway, resulting in at least partial retention of enzyme function (Fig. 1) [6, 18]. We propose that systematic review of these disorders will identify patterns and information of prognostic value that will be applicable to mt-aaRSrelated disorders that are more recently emerging.

\section{LBSL}

Leukoencephalopathy with brainstem and spinal cord involvement and lactate elevation (LBSL) is typically characterized by slowly progressive gait difficulty secondary to spasticity, ataxia, and proprioceptive deficits with clear neuroimaging correlates in the pyramidal tracts, cerebellum, and dorsal columns [19, 20]. The hallmark diagnostic features are identification of a DARS2 mutation, which encodes mitochondrial aspartyl-tRNA synthetase, and a highly characteristic pattern of white matter changes on MRI. A lactate peak on proton magnetic resonance spectroscopy (MRS) is often reported. LBSL presents as a clinical syndrome on a spectrum from mild to severe phenotypes [21, 22].

DARS2 encodes mitochondrial aspartyl-tRNA synthetase (mtAspRS), the enzyme that attaches aspartate to the correct mitochondrial tRNA. This step is a necessary prerequisite in the translation of mitochondrial mRNA into functional protein. The DARS2 mutation inheritance pattern is autosomal recessive, and strikingly, nearly all affected individuals have two compound heterozygous DARS2 mutations, one of which is in most cases a splice site mutation in intron 2, upstream of exon $3[6,19]$. The consequence of this mutation type is that exon 3 is not included in the mRNA, leading to a frameshift, premature stop, and absence of functional protein. However, these splice site mutations are suspected to be "leaky," so that for some proportion of the mRNA formed, exon 3 is appropriately included and a normal full-length protein is produced [15]. The disease is very rare, but there is an especially high-carrier rate of DARS2 mutations (1:95) in Finland, for reasons that have not yet been elucidated [23]. Over 60 different pathogenic DARS2 mutations have been reported to date, and accordingly, there is great heterogeneity in the 
combinations of mutations that are causal in LBSL [22, $24,25]$. Although most LBSL cases are due to compound heterozygous DARS2 mutations, a small subset of patients with homozygous DARS2 mutations have been reported [7, 26-28].Thus, those carrying homozygous mutations do not necessarily die intrauterinely, but may present with a similar phenotype as patients carrying a compound heterozygous mutation.

Regarding the selective vulnerability of nervous system tracts in LBSL, analysis of intron 2 splice site mutations showed that the correct inclusion of exon 3 in the normal aspartyl-tRNA synthetase (mtAspRS) mRNA occurs much less efficiently in neural cells relative to other cell types [29]. In an elegant transgenic mouse model in which DARS2 was depleted in either forebrainhippocampal neurons or myelin-producing cells, it was shown that DARS2 depletion in adult neurons leads to a significant mitochondrial dysfunction and progressive neuronal apoptosis [30]. On the other hand, oligodendrocytes deficient in DARS2 were seemingly resistant to apoptosis despite dramatic respiratory chain deficiency, indicating that LBSL disease is predominantly due to neuronal pathology. Analysis of DARS2 missense mutations on the expression, enzyme activity, localization, and dimerization of mtAspRS revealed varying effects on this enzyme's properties. Most missense mutations resulted in at least a small reduction of mitochondrial aspartylation activity within human cells [15, 29]; however, the alteration of mtAspRs activity was not clearly correlated with disease severity. The implication for treatment is that it will be challenging to develop a single, common therapy to target the varied effects that the missense mutations impose on mtAspRS activity. Therefore, the more efficient approach would be to trial interventions that increase correct splicing of exon 3.

\section{Neuroimaging in LBSL}

There is a very characteristic pattern of supratentorial, infratentorial, and spinal cord white matter involvement in LBSL, in particular, there is high T2 signal "demarcation" of the involved neuroanatomical pathways. The cerebral and cerebellar white matter, corticospinal tracts, superior and/or inferior cerebellar peduncles, medial lemniscus, pyramids, lateral corticospinal tracts, and dorsal columns are most frequently affected (Fig. 2, Table 4). Most patients also have an MRS finding of lactate elevation in the abnormal white matter $[6,19,20$, 32]. It is not fully understood if LBSL results from myelin loss or a disruption of myelin development. Only one post-mortem examination of the brain has been done in a severely affected LBSL infant patient and showed widespread loss of myelin in the cerebral and cerebellar white matter with reactive astrocytes and foamy macrophages. Gray matter structures were preserved except for the globus pallidus [33]. A growing body of neuroimaging evidence suggests the lesions reflect a predominant demyelination [34, 35]. First, a demyelinating process may explain the lack of gray matter lesions. Diffusionweighted imaging in a case of two affected sisters showed uniformly increased lesional water diffusion, suggesting increased extracellular water levels secondary to myelin degeneration [35]. In a case report of an LBSL patient who underwent serial imaging, compared to the initial MRI, restricted diffusion appeared at the lesion edges, where there was a dark ADC map, although at the center of the lesion the ADC signal had increased, which also suggests demyelination [26]. Furthermore, serial imaging of three LBSL patients demonstrated progressive loss of white matter volume only [31]. In magnetic resonance spectroscopy studies, the frontal and cerebellar white matter shows elevated lactate (Lac), reduced $\mathrm{N}$-acetyl acetate (NAA), increased myoinositol (mI), and mildly elevated choline-containing compounds (Cho). Decrease in NAA and increase in $\mathrm{mI}$ in MRS suggests axonal damage or loss and gliosis, while elevation of Cho suggests low-grade demyelination [34].

There is evidence for an association of the MRI features and clinical phenotype, such that in late onset, mildly affected patients, the cerebral white matter abnormalities are less profound than in severely affected patients [22, 36-38]. However, it is unclear if the location or severity of MRI lesions is predictive of disease progression $[39,40]$.

\section{LBSL patterns of disease progression}

The clinical severity in LBSL ranges from infantile onset, rapidly fatal disease to adult onset, slow and mild disease [22] (Table 2). However, the most common presentation of LBSL is slowly progressive deterioration of motor skills and in some cases cognitive skills beginning in childhood or adolescence [36]. In a longitudinal followup study of a large cohort of LBSL patients, the vast majority developed unsupported walking at an expected age. By adulthood, 50\% required walking aids and 13\% were wheelchair dependent. In general, earlier onset of symptoms predicted more severe neurological deterioration in the first decade after disease onset [22]. Case reports of affected siblings have shown that both mild and severe disease phenotypes can manifest even when the DARS2 mutations are identifical [41, 42].

The overall disease prevalence and frequency of key clinical features in LBSL is reported in Table 3. The lower limbs are primarily affected in LBSL. Leg spasticity, ataxia, hyperreflexia, weakness, and atrophy of the leg muscles have been reported for the majority of LBSL patients. Fine motor skills are generally less severely affected than ambulation [22, 36, 43]. Impaired proprioception, sphincter dysfunction, and urge incontinence 


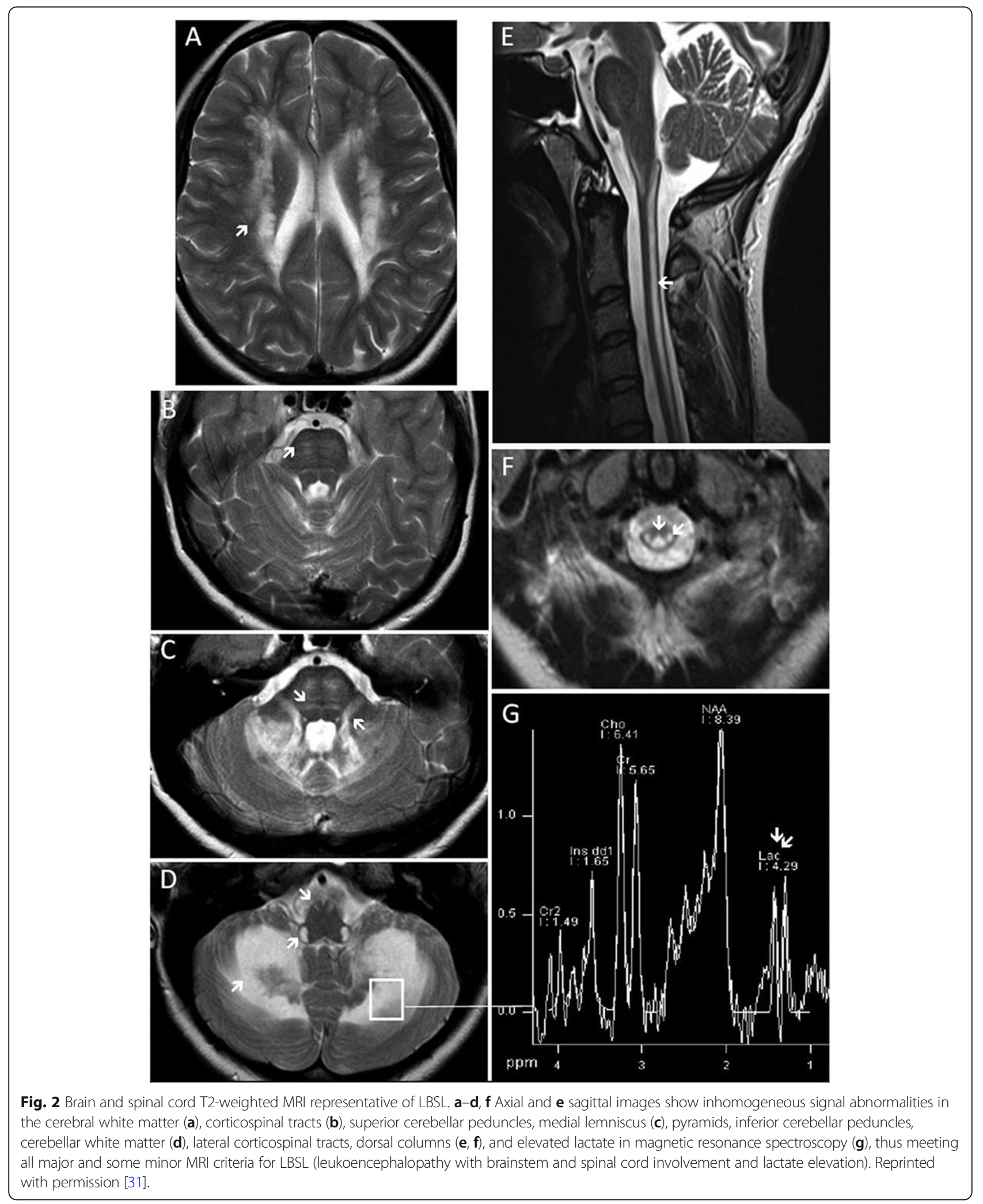


Table 2 Natural history of mt-aaRS-related leukodystrophies

\begin{tabular}{|c|c|c|c|}
\hline & LBSL & LTBL & AARS2 \\
\hline Mean age at onset (age range) & 8 years (5 months -40 years) & 6 months (birth-16 months) & 25 years ( $1.5-44$ years) \\
\hline $\begin{array}{l}\text { Rate of disease } \\
\text { progression }\end{array}$ & $\begin{array}{l}\text { Slow, gradual }> \\
\text { rapid decline }\end{array}$ & $\begin{array}{l}\text { Biphasic with stability or improvement } \\
\text { after early "hit" }\end{array}$ & Rapid decline within a few years \\
\hline Risk of disability & $\begin{array}{l}\text { Greater disability associated } \\
\text { with earlier age of onset }\end{array}$ & $\begin{array}{l}\text { Greater disability associated with initial } \\
\text { clinical and imaging severity }\end{array}$ & $\begin{array}{l}\text { High risk of motor and cognitive } \\
\text { impairment }\end{array}$ \\
\hline Risk of mortality & $\begin{array}{l}\text { Increased for infantile-onset } \\
\text { disease, otherwise low }\end{array}$ & $\begin{array}{l}\text { Increased for early onset, severe disease } \\
\text { with multi-organ involvement }\end{array}$ & Increased risk from late disease complications \\
\hline
\end{tabular}

are often present. Seizures occur in some patients, which is consistent with an increased frequency of epilepsy for many mitochondrial disorders [44, 45]. More recently, involvement of the visual system has been reported, including optic atrophy, hypoacusis, and diplopia [46]. Furthermore, exercise-induced ataxia and fever [7] and motor deterioration after minor head trauma or after infection have been described [26].

Table 3 lists the number of cases of each disorder reported in the literature and the prevalence of the clinical signs of disease as a percentage of these cases.

Most patients have normal cognitive ability, although a higher proportion than expected among the general population require special education and serious intellectual disability has occasionally been reported $[8,19$, 22]. A longitudinal study of a series of LBSL patients who had neuropsychological testing in adulthood revealed a cognitive profile for each that was similar to that reported in patients with multiple sclerosis [47], namely impairment of information-processing speed and working memory.

Few medications have been trialed to prevent LBSL disease progression or promote recovery from a metabolic crisis. Diplopia appeared to be steroid-responsive in a patient with adult-onset LBSL [46]. Exercise- induced paroxysmal gait ataxia and areflexia showed a dose-dependent sustained treatment response to a carbonic anhydrase inhibitor [7]. The drug cantharidin, a protein phosphatase 1 and $2 \mathrm{~A}$ inhibitor and splicing modulator, has been shown to affect intron 2/exon 3 event splicing, which is the most common mutation in LBSL [22, 48]. Cantharidin itself is too toxic for human use, but less toxic variants and alternative protein phosphatase 1 or $2 \mathrm{~A}$ inhibitors are under investigation $[9,49,50]$.

\section{LTBL}

A detailed clinical and imaging review of leukoencephalopathy with thalamus and brainstem involvement and high lactate (LTBL) cases reveals both a mild and severe disease phenotype caused by either heterozygous or homozygous EARS2 mutations, which encode mitochondrial glutamyl-tRNA synthetase $[18,51]$. All patients typically experience infantile onset, rapidly progressive disease with severe MRI abnormalities and increased lactate in serum and proton magnetic resonance spectroscopy. Whereas mildly affected patients partially recover and make developmental progress over the next few years with associated MRI improvement and declining lactate levels, severely affected patients experience a

Table 3 Clinical features of mt-aaRS-related leukodystrophies

\begin{tabular}{llll}
\hline & LBSL $(n=128)$ & LTBL $(n=21)$ & $\begin{array}{l}\text { AARS2 }(n=16) \\
\text { \% of cases reported }\end{array}$ \\
\hline Sex (male) & \% cases reported & of cases reported & 56 \\
Cognitive impairment or learning problems & 45 & 62 & 94 \\
Motor or gait impairment & 30 & 100 & 88 \\
Seizures & 94 & 100 & 8 \\
Psychiatric/behavior problems & 7 & 43 & 93 \\
Incontinence & Not reported & n/a & 0 \\
Sensory changes & 4 & Not reported & 13 \\
Ovarian failure (female) & 67 & n/a & 100 \\
Cardiac disease & 0 & 0 & 6 \\
Visual/auditory impairment & 0 & 14 & 6
\end{tabular}


stagnant clinical course, associated with MRI brain atrophy and persistently high lactate (Figs. 3 and 4).

In a study of biochemical assays of individual mitochondrial respiratory chain complexes (RCC) in cultured fibroblasts of LTBL patients, there was a spectrum of moderate reduction of RCC activity to virtually undetectable activity in some complexes (Fig. 1) [18, 31]. Thus, the authors proposed that the decreased cellular oxygen consumption rate and inversely increased lactate production is likely the effect of cumulative impairment of respiration by the whole set of mitochondrial respiratory chain complexes. Assays have not yet been performed in LTBL neuronal cells, which would permit insight into the effects of specific mutations on overall mt-aaRS activity in these especially vulnerable cells.

\section{LTBL neuroimaging}

MRI pattern recognition paired with whole-exome sequencing first defined LTBL, which features extensive symmetrical cerebral white matter abnormalities sparing the periventricular rim and symmetrical signal abnormalities of the consistently affected corpus callosum, basal ganglia, thalami, midbrain, pons, medulla, and cerebellar white matter $[10,16,18,51]$ (Table 4). Some patients also exhibit dysplasia and/or agenesis or thinning of the posterior corpus callosum, and the cerebral white matter is initially more diffusely abnormalappearing and edematous. Proton magnetic resonance spectroscopy shows increased lactate in affected brain regions. The lesional pathology in LTBL remains unclear, although imaging studies mostly support a process of delayed myelination. An early infantile case showed mildly elevated T2 and T1 signal in the subcortical white matter, indicating lack of myelin deposition. In subsequent studies, the T2 hyperintensity faded, indicating myelin deposition was occurring, albeit at a delayed timepoint [18]. Moreover, reports of cases with the absence of the thalami or parts of the corpus callosum support the theory that damage occurs to these structures antenatally, causing disruption of further development [52].

Table 4 lists the prevalence of radiologic signs of disease based on percentage of cases reported in the literature.

\section{LTBL disease progression}

In the mild LTBL variant, associated with either EARS2 heterozgous or homozygous mutations, initially, there is

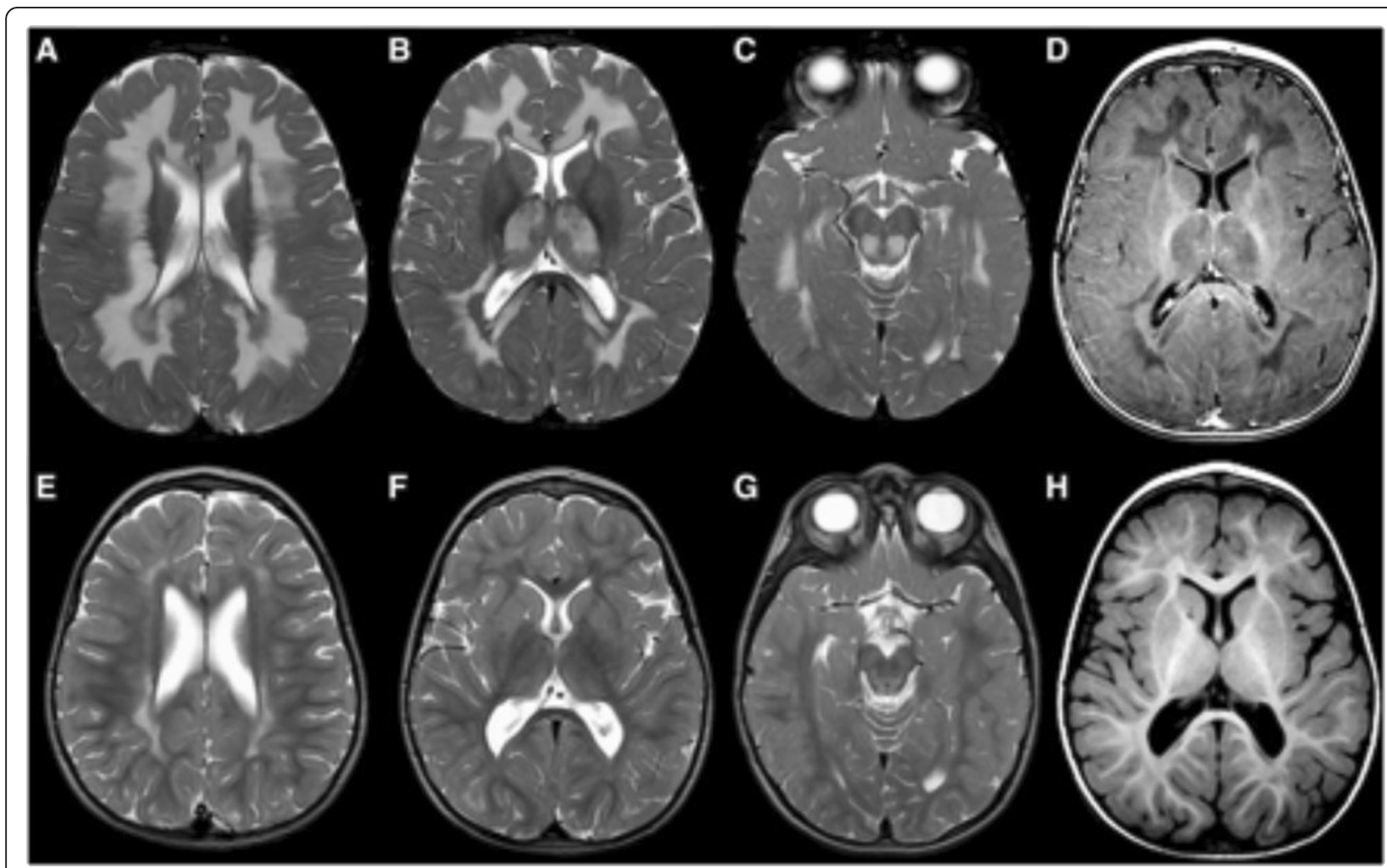

Fig. 3 Brain T2-weighted MRI representative of mild LTBL. Axial $T_{2^{-}}(\mathbf{a}-\mathbf{c}$ and $\mathbf{e}-\mathbf{g})$ and $T_{1}$-weighted images $(\mathbf{d}$ and $\mathbf{h})$ in (EARS2) patient 6 with a mild disease course at 11 months $(\mathbf{a}-\mathbf{d})$ and 3 years $(\mathbf{e}-\mathbf{h})$. Note the extensive $T_{2}$-hyperintense and $T_{1}$-hypointense signal of the deep cerebral white matter with sparing of a periventricular $\operatorname{rim}(\mathbf{a}, \mathbf{b}$, and $\mathbf{d})$. There are also signal abnormalities in the thalami $(\mathbf{b})$ and dorsal part of the midbrain (c). Note the impressive improvement 2 years later $(\mathbf{e}-\mathbf{h})$. Reprinted with permission [45] 


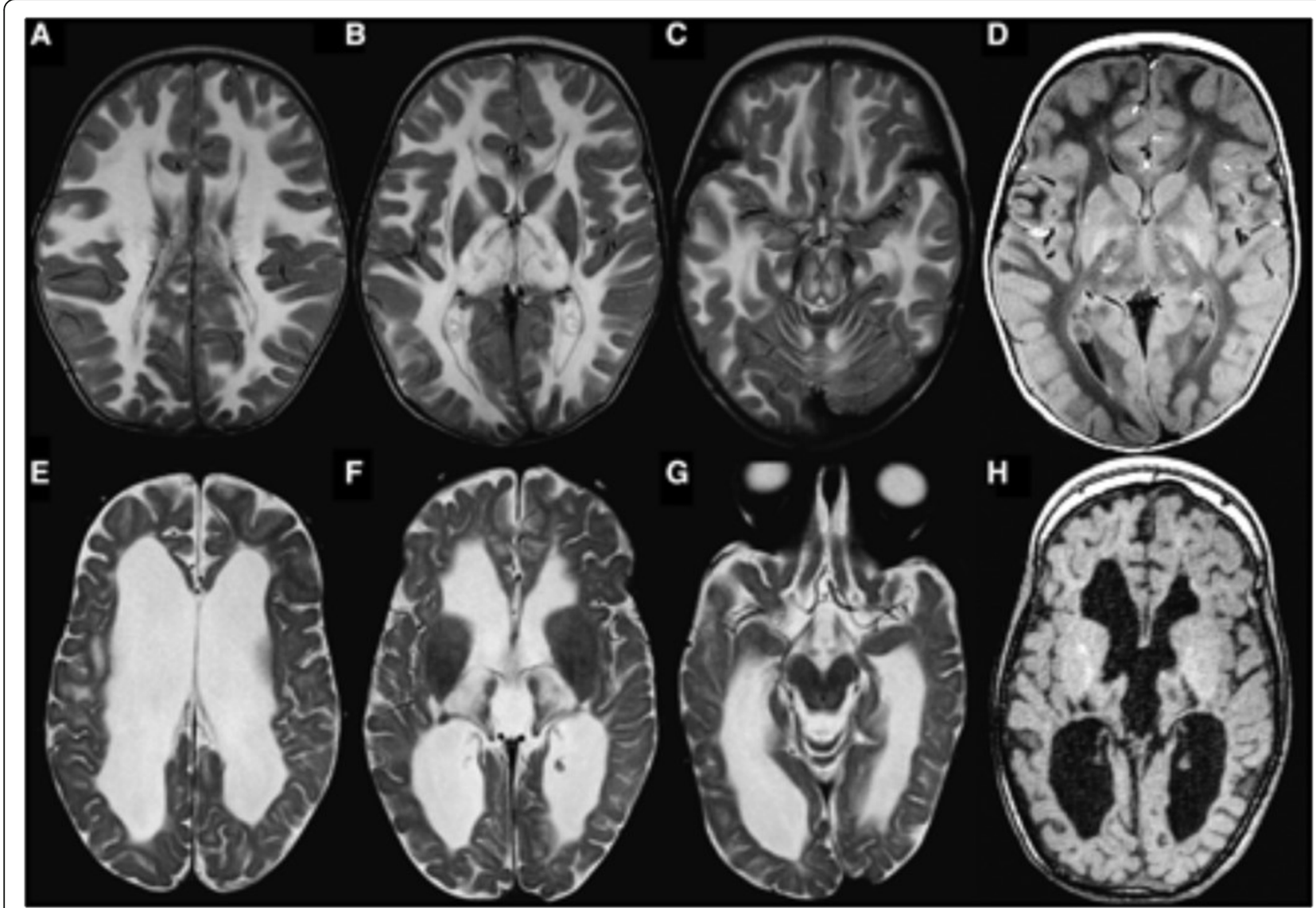

Fig. 4 Brain T2-weighted MRI representative of severe LTBL. Axial $T_{2^{-}}(\mathbf{a}-\mathbf{c}$ and $\mathbf{e}-\mathbf{g})$ and $T_{1}$-weighted images (d and $\left.\mathbf{h}\right)$ in (EARS2) patient 9 at 8 months (a-d) and 4 years $(\mathbf{e}-\mathbf{h})$. Note the diffuse $\mathrm{T}_{2}$-hyperintense and $\mathrm{T}_{1}$-hypointense signal of the cerebral white matter, only sparing a periventricular $\operatorname{rim}(\mathbf{a}, \mathbf{b}$, and $\mathbf{d})$. There are also signal abnormalities in the thalami $(\mathbf{b})$ and the midbrain $(\mathbf{c})$. Three years later, there is a serious atrophy of the cerebral white matter and thalami (d, e, and $\mathbf{h})$. The midbrain signal abnormalities have disappeared (f). Reprinted with permission [45].

a developmental delay, hypotonia, and poor feeding in infancy. Most patients experience early milestone regression prior to onset of clear, rapid neurological deterioration marked by spasticity and ataxia $[10,16,18]$ (Tables 2 and 3). This phase is followed by partial recovery of lost motor and cognitive skills. The majority of patients have some residual spasticity perhaps requiring walking aids. Cognitive ability ranges from average to mild impairment $[10,16,53]$. As the clinical status improves, the MRI abnormalities also partially resolve.

A subset of LTBL patients experience onset of neurological impairment in the neonatal period, characterized by global failure to attain milestones, severe axial hypotonia, dysphagia, and often progression to spastic tetraparesis $[18,51,52,54]$. There may be development of seizures. Although their symptoms stabilize over time, there is no clear recovery of neurologic function. Neuroimaging demonstrates more significant radiographic abnormalities, such as atrophy of the brain, brainstem or cerebellum, and corpus callosum dysgenesis, with associated high lactate on MRS. This severe phenotype has been associated with both homozygous and heterozygous EARS2 mutations. The progression of LTBL has also been characterized by early, rapid neurological deterioration, severe lactic acidosis, and multi-systems disease, which may lead to fatal cardiorespiratory failure $[55,56]$. In the acute resuscitation phase, a standard treatment regimen for mitochondrial disorders has been administered, including thiamine, riboflavin, and coenzyme Q 10, but no long-term interventions have been developed.

\section{AARS2-related leukoencephalopathy}

$A A R S 2$ leukoencephalopathy is attributed to a defect in mitochondrial alanyl-tRNA synthetase, only compound heterozygous mutations have been reported [57-59]. The classic presentation of AARS2 (ovario) leukoencephalopathy is a childhood-to-adulthood onset of neurologic deterioration with features of ataxia, spasticity, cognitive decline, and later in the disease course, frontal lobe impairment that manifests as psychiatric disorders 
Table 4 Radiologic features of mt-aaRS-related leukodystrophies

\begin{tabular}{|c|c|c|c|}
\hline & $\begin{array}{l}\text { LBSL }(n=128) \\
\% \text { of cases reported }\end{array}$ & $\begin{array}{l}\text { LTBL }(n=21) \\
\% \text { of cases reported }\end{array}$ & $\begin{array}{l}\text { AARS2 }(n=16) \\
\% \text { of cases reported }\end{array}$ \\
\hline \multicolumn{4}{|l|}{ Imaging pattern } \\
\hline Asymmetric & 0 & 0 & 87 \\
\hline Symmetric & 100 & 100 & 13 \\
\hline \multicolumn{4}{|l|}{$\begin{array}{l}\text { Distribution of T2/FLAIR signal } \\
\text { abnormalities }\end{array}$} \\
\hline Cortical WM & $\begin{array}{l}100 \text { (frontal, parietal or diffuse } \\
\text { predominance) }\end{array}$ & 100 (predominantly diffuse) & $\begin{array}{l}100 \text { (fronto-parietal } \\
\text { predominance) }\end{array}$ \\
\hline Periventricular WM & 100 & $\begin{array}{l}9 \text { (periventricular rim usually } \\
\text { spared) }\end{array}$ & 87 \\
\hline Subcortical WM & 100 & 61 & $\begin{array}{l}7 \text { (rare subcortical U-fiber } \\
\text { involvement) }\end{array}$ \\
\hline Corpus callosum & 79 & 95 & 100 \\
\hline Pyramidal tracts & 99 & 14 & 81 \\
\hline Brainstem & 100 (medullary tract predominance) & 95 & 63 \\
\hline Cerebellum & 97 & 83 & 27 \\
\hline Basal ganglia & 8 (caudate or putamen) & $\begin{array}{l}62 \text { (caudate, putamen, or globus } \\
\text { pallidus) }\end{array}$ & 39 (caudate) \\
\hline Thalamus & 0 & 100 & Not reported \\
\hline \multicolumn{4}{|l|}{ Lesion characteristics } \\
\hline Diffusion restriction of any tract & 82 & 38 & 87 \\
\hline Atrophy & 3 (adult patients) & 27 & 77 \\
\hline Elevated lactate on MR spectroscopy & 83 & 71 & 20 \\
\hline
\end{tabular}

or executive dysfunction. All affected female patients develop ovarian failure.

\section{AARS2 neuroimaging}

The MRI typically shows a leukoencephalopathy with a significant involvement of left-right connections, descending tracts, and cerebellar atrophy [57, 60, 61]. MRI signal abnormalities are primarily found in frontal and parietal white matter, deep white matter, and the corpus callosum (Table 4, Fig. 5). Neuroimaging suggests that the pathology underlying white matter signal abnormalities is demyelination, although post-mortem tissue has not been studied. MR spectroscopy and diffusionweighted imaging (DWI), reported only in one patient thus far, reflected the presence of active demyelination with an elevated lactate peak, high choline-containing compounds, and lesional DWI/ADC maps indicative of restricted diffusion [60]. Furthermore, the presence of spots of restricted diffusion in the cerebral white matter has a similar appearance to LBSL lesions and is ascribed to myelin vacuolization, which is commonly seen in mitochondrial leukodystrophies [57].

\section{AARS2 leukoencephalopathy disease progression}

The onset of symptoms usually occurs in the 3rd or 4th decade of life, starting with cognitive decline, mood, or behavioral problems then the development of signs consistent with frontal lobe dysfunction, such as stereotypies and apraxia, and motor impairment $[57,61]$ (Table 2). For affected women, ovarian failure is typically the first sign of disease. Spasticity is the most consistent finding and dystonia, dysarthria, or tremor may also be present. When the cerebellum is involved, ataxia or nystagmus appear. There may be rapidly progressive motor impairment with no evidence of cognitive regression or cognitive deterioration without motor dysfunction. Typically, within 5-10 years, these patients advance to the point of no or limited interaction with the environment, nonambulatory status, and in many cases, premature death $[58,59,62]$.

A smaller group of patients have exhibited motor or cognitive delays as early as infancy or childhood. In these cases, despite impaired balance, clumsiness, or learning difficulties, their clinical course remained stable until the teenage years, at which time rapid progression of motor, cognitive, and psychiatric impairment began [57]. One recent case presented with onset of bilateral optic atrophy and retinopathy in late infancy [63]. In addition to supratentorial and cerebellar multifocal white matter changes, there were signal changes in the dorsal columns of the spinal cord, a novel finding in this disease. The exam was notable for absent patellar reflexes 

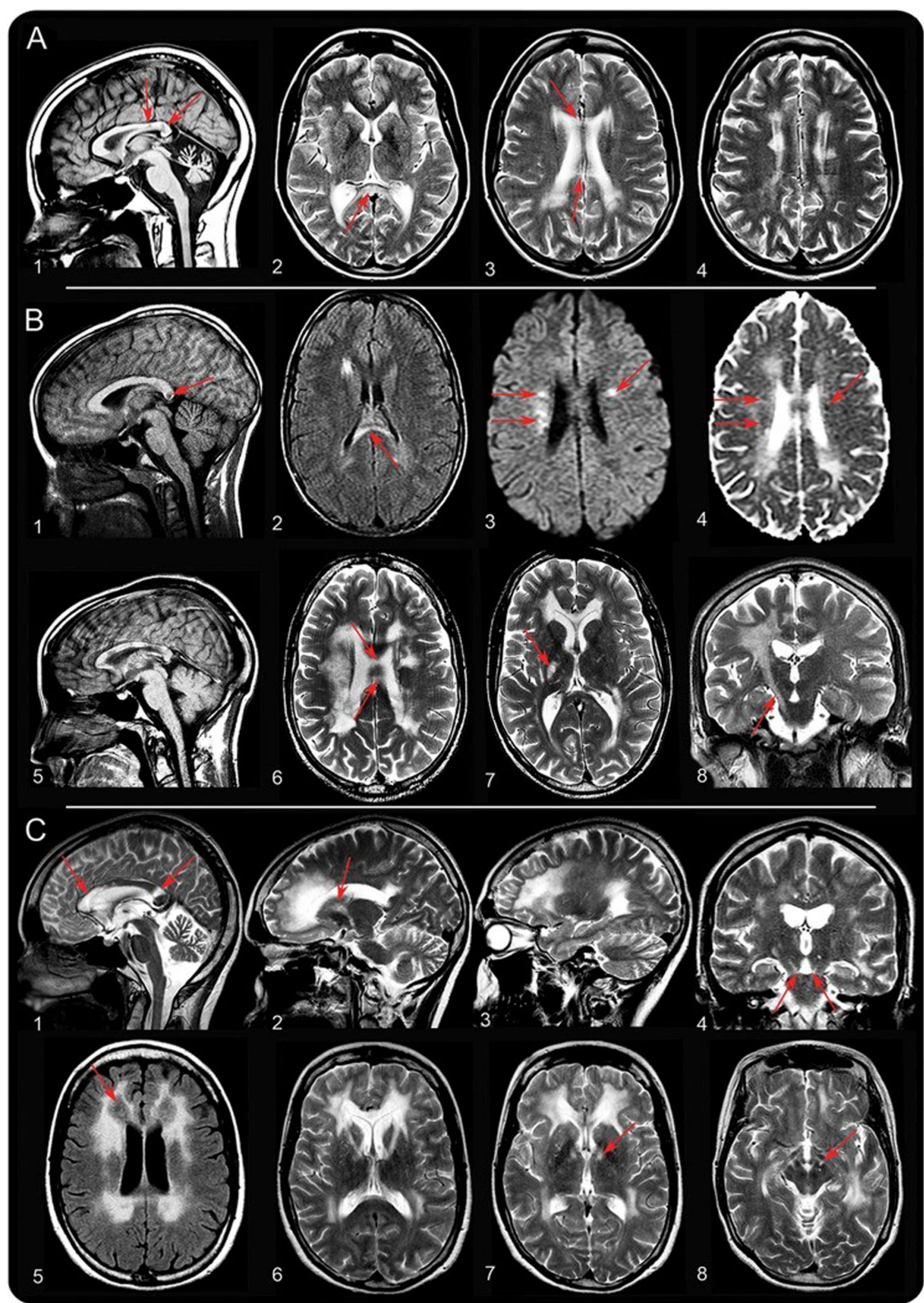

Fig. 5 (See legend on next page.) 
(See figure on previous page.)

Fig. 5 Brain and spinal cord T2-weighted MRI representative of AARS2-related leukodystrophy. a MRI in (AARS2 patient) P1 at age 28. The sagittal T1-weighted image shows serious cerebellar atrophy and 2 strips of abnormal signal in the splenium (arrows in image 1). The axial T2-weighted images show inhomogeneous areas of abnormal signal in the periventricular white matter. The areas on the left and right are connected signal abnormalities in the corpus callosum (arrows in images 2-4). b MRI in (AARS2 patient) P2 at age 14 (images 1 and 2), age 21 (images 3 and 4), and age 23 (images 5-8). At age 14, a lesion is seen in the splenium of the corpus callosum (arrow in image 1) and in the right frontal periventricular white matter. The diffusion-weighted images suggest the presence of multiple small areas of restricted diffusion in the abnormal white matter (arrows in image 3), confirmed by low signal of the corresponding areas on the apparent diffusion coefficient map (arrows in image 4). The most recent MRI shows multiple segments of abnormal signal in the corpus callosum (image 5 and arrows in image 6). More extensive signal abnormalities are seen in the periventricular white matter, especially on the right (images 6 and 7). Signal abnormalities extend downward through the posterior limb of the internal capsule and the pyramidal tracts in the brainstem on the right (arrows in images 7 and 8). c MRI in (AARS2 patient) P3 at age 35 . The midsagittal image shows that the anterior part of the corpus callosum is abnormal, whereas only a strip of signal abnormality is seen in the splenium (arrows in image 1). Images 2 and 3 illustrate that the frontal and parietal white matter is abnormal, whereas the central white matter in between is normal. The tract involvement is evident (arrows in images 2 and 4). The axial fluid-attenuated inversion recovery image shows that the affected white matter is rarefied (arrow in image 5). The axial T2-weighted images illustrate the involvement of the anterior limb of the internal capsule (image 6) and the frontopontine tracts going down into the brainstem (arrows in images 7 and 8). Reprinted with permission [10]

and normal strength and sensation, but electromyogram revealed a motor demyelinating polyneuropathy.

Although it was previously thought that AARS2 also causes an isolated, infantile onset cardiomyopathy without brain involvement, and one case has been reported with brain imaging signal abnormalities and atrophy as well as cardiomyopathy, lactic acidosis, and early death [64-67]. Therefore, investigation of the brain in infant patients who present with cardiomyopathy is worthwhile. The reported prevalence of key features of AARS2-leukodystrophy is listed in Table 3. No treatments for AARS2 leukoencephalopathy have been systematically studied.

\section{Discussion}

The disease patterns that are emerging for different mt-aaRS mutations, even in small cohorts of patients are quite distinct (Tables 2 and 3). The LBSL natural history generally features slowly progressive motor and cognitive deterioration after onset in childhood. The LTBL disease course is biphasic, involving one "hit" in the neonatal or infantile period with either stability or recovery based on the degree of MRI brain insult. AARS2 leukoencephalopathy is characterized by relatively late onset of significant disease with rapid progression to motor and cognitive disability. Despite these differences, some common themes are present. Homozygous variants are present in each of these disorders and may manifest a disease phenotype anywhere along the spectrum. Siblings with the same set of mutations may be quite variably affected. Early onset of symptoms is often associated with more widespread or significant structural brain abnormalities. Accordingly, significant brain abnormalities are more often associated with faster neurological deterioration and ultimately greater disability. On the other hand, clinical recovery, if it occurs, is often paralleled by improvement in restricted diffusion, T2/FLAIR hyperintensity, and MRS lactate peak on serial imaging. Systemic involvement, especially in younger onset cases, is common and has important implications for morbidity and mortality.
It is not known what factors contribute to early and late onset forms of these disorders, but as previously noted, earlier disease onset is often correlated with more severe brain abnormalities that appear to have occurred early in development. Thus far, the rarity of the mt-aaRS diseases and high number of private mutations has precluded the establishment genotype-phenotype associations. Available evidence in a cohort of 66 LBSL patients suggests that the genotype influences the phenotype; in particular, some combinations of mutations were consistently associated with a mild phenotype, but larger numbers of patients are needed to confirm this [22]. One theory is that some combinations of the two compound heterozygous mutations may lead to a more profound loss of mt-aaRS enzyme activity than others, leading to greater mitochondrial respiratory chain complex dysfunction. Given that carriers are asymptomatic and many affected patients have symptoms that do not affect their survival or mobility until after young adulthood, it is plausible that compound heterozygous mutations are the primary inheritance mode.

As illustrated in Fig. 1, decreased EARS2 and AARS2 enzyme activity in cultured cells leads to decreased function of specific mitochondrial respiratory chain complexes, presumably because of misfolding of RCC proteins. Furthermore, in LTBL, there are measured decreases in the cellular oxygen consumption rate. Therefore, the leading theory is that the increased lactate production is secondary to these cumulative defects in mitochondrial respiration. Indeed, the finding of lactate elevation is not required for diagnosis of any of these disorders, and although the majority of patients exhibit elevated lactate on MRS, the levels appear to fluctuate over time. Furthermore, lactate elevation is known to be a non-specific marker of mitochondrial disease [68].

Beyond their canonical function of directly altering tRNA charging, thereby facilitating the translation of proteins that form the mitochondrial respiratory chain complexes (Fig. 1), it is also possible that the mt-aaRS 
affect non-canonical biochemical pathways in neurons, such as those involved in cell signalling, transcription, or rRNA biogenesis $[69,70]$. In humans, two sets of distinct nuclear genes code for either the cytosolic aaRSs or the mitochondrial aaRSs [71]. Cytosolic aaRSs have roles in numerous non-canonical cellular functions beyond translation, such as angiogenesis, immune responses, inflammation, tumorigenesis, and neuronal development [72, 73]. Similarly, reports of non-canonical roles for the mt-aaRS are beginning to emerge, such as a proangiogenic function for rat mitochondrial tryptophanyltRNA synthetase (WARS2) [74] and a possible role for mt-aaRS mutations in the integrated stress response (ISR) [75]. The ISR is a highly conserved homeostatic program in eukaryotic cells that is activated in response to a diversity of pathologic states or cellular stresses. Agnew et al. postulated that activation of the ISR through alternative mechanisms is dependent on the degree of mitochondrial translation inhibition [75]. Complete inhibition of mitochondrial translation in DARS2 knockout mice results in the accumulation of unassembled nuclear-encoded respiratory chain subunits, causing severe proteostatic stress and UPR ${ }^{\mathrm{mt}}$-dependent ISR activation [76]. In this model, there is failure of the ISR to achieve homeostasis, resulting in severe cardiac disease and decreased survival. However, partial inhibition of mitochondrial translation in a WARS2 mouse model leads to ISR activation due to respiratory chain dysfunction and loss of mitochondrial membrane potential, resulting in a more mild cardiac phenotype and increased survival [75].

Further evidence that malfunction of the mitochondrial translational machinery promotes pathologic ISR activation in white matter disease comes from the study of disease mechanisms in Vanishing White Matter Disease (VWMD). VWMD is a severe progressive leukodystrophy with episodic clinical deterioration due to mutations in the five genes that encode the subunits of the elongation initiation factor complex EIF2B [77-80]. EIF2B is a key regulator of mRNA translation [81, 82]. Interestingly, EIF2B is also a regulator of the ISR and abnormal ISR response is thought to be the main underlying pathomechanism in VWMD [83-85]. Many EIF2B mutations in VWMD have no clear effect on the enzyme's activity or complex formation [86-88]. However, some VWMD mutations destabilize the decameric eIF2B holoenzyme and impair its enzymatic activity. In a mouse VWMD model, an ISR inhibitor (ISRIB) blocked ISR activation, stabilized VWMD mutant eIF2B in the decameric form, and restored normal catalytic activity [89]. Similar to the mt-aaRS disorders, it is unclear why VWMD selectively affects the white matter [90]. Recent investigations have shown that VWMD astrocytes appear toxic to neurons and oligodendrocytes and show impaired maturation [91, 92]. Mutation of EIF2B in VWMD mutant mice resulted in ISR upregulation in both astrocytes and oligodendrocytes that preceded myelin loss and motor deficits [93]. Such mechanistic studies have not yet been attempted in the mt-aaRS leukodystrophies.

\section{Conclusion}

The significant clinical variability and tissue specificity found within each mt-aaRS disorder highlight the importance of understanding the factors influencing mitochondrial translation in different cell types. Overall, the effects of mt-aaRS mutations on the process of translation may be subtle and difficult to dissociate, especially given the high number of private mutations. Furthermore, there is a growing rationale to explore potential non-canonical roles of the mt-aaRSs in immune regulation, inflammation, and neuronal differentiation. Mechanistic studies are challenging, especially since it appears that some of the mutation effects are specific to a neuronal or glial context, and obtaining patient cells that can be cultured for this purpose is cost and labor intensive.

\section{Abbreviations \\ Cho: Choline-containing compounds; ISR: Integrated stress response; ISRIB: ISR inhibitor; LBSL: Leukoencephalopathy with brainstem and spinal cord involvement and high lactate; LTBL: Leukoencephalopathy with thalamus and brainstem involvement and high lactate; Mi: Myoinositol; MRR: Mitochondrial respiratory rate; MRS: Magnetic resonance spectroscopy; mt-aaRSs: Mitochondrial aminoacyl-tRNA synthetase proteins; mtAspRS: Mitochondrial aspartyl-tRNA synthetase; NAA: N-acetyl acetate; OCR: Oxygen consumption rate; RCC: Respiratory chain complex; WWMD: Vanishing White Matter Disease; WARS2: Mitochondrial tryptophanyl- tRNA synthetase}

\section{Acknowledgements}

Not applicable

\section{Authors' contributions}

AS wrote the initial drafts of the manuscript and tables. CN performed major manuscript edits and contributed to imaging figure selection and generated Fig. 1. MK performed the manuscript and table edits and generated Fig. 1. AF performed significant manuscript edits and added elements to the discussion. All authors read and approved the final manuscript.

\section{Funding}

Kennedy Krieger Institute IDDRC, Director Mark Mahone, US4HD079123 T32, Research Training in Rehabilitation for Brain Injury and Neurological Disability, PI Amy Bastian MD, Fellow Amena Smith MD PhD. Project Number 5T32HD007414-25. 08/2018-08/2019 R01 NS097511-01, Targeted Therapies for Neonatal White Matter Injury, PI Ali Fatemi, MD MBA. Original research data was not generated to contribute to this manuscript, but the funding sources support the authors academic appointments.

Availability of data and materials

Data sharing is not applicable to this article as no datasets were generated or analyzed during the current study.

Ethics approval and consent to participate Not applicable

Consent for publication

Not applicable 


\section{Competing interests}

Regarding interests to declare, Dr. Fatemi is a paid drug safety monitoring board member for Bluebird Bio, Stealth Biotherapeutics, and paid consultant to Calico Labs. All other authors declare that they have no competing interests.

\section{Author details}

'Moser Center for Leukodystrophies at the Kennedy Krieger Institute, Baltimore, MD 21205, USA. ${ }^{2}$ Department of Neurology and Developmental Medicine, Kennedy Krieger Institute, Baltimore, MD 21205, USA. ${ }^{3}$ Department of Neurology, Johns Hopkins University School of Medicine, Baltimore, MD 21287, USA.

Received: 18 February 2019 Accepted: 11 November 2019 Published online: 16 December 2019

\section{References}

1. Boczonadi V, Ricci G, Horvath R. Mitochondrial DNA transcription and translation: clinical syndromes. Essays Biochem. 2018;62(3):321-40 Epub 2018/07/08.

2. Gorman GS, Chinnery PF, DiMauro S, Hirano M, Koga $Y$, McFarland R, et al. Mitochondrial diseases. Nat Rev Dis Primers. 2016;2:16080 Epub 2016/10/25.

3. Ognjenovic J, Simonovic M. Human aminoacyl-tRNA synthetases in diseases of the nervous system. RNA biology. 2018;15(4-5):623-34 Epub 2017/05/24

4. Meyer-Schuman R, Antonellis A. Emerging mechanisms of aminoacyl-tRNA synthetase mutations in recessive and dominant human disease. Hum Mol Genet. 2017;26(R2):R114-R27 Epub 2017/06/22.

5. Sissler M, Gonzalez-Serrano LE, Westhof E. Recent advances in mitochondrial aminoacyl-tRNA synthetases and disease. Trends in molecular medicine. 2017;23(8):693-708 Epub 2017/07/19.

6. Scheper GC, van der Klok T, van Andel RJ, van Berkel CG, Sissler M, Smet J, et al. Mitochondrial aspartyl-tRNA synthetase deficiency causes leukoencephalopathy with brain stem and spinal cord involvement and lactate elevation. Nature genetics. 2007;39(4):534-9 Epub 2007/03/27.

7. Synofzik M, Schicks J, Lindig T, Biskup S, Schmidt T, Hansel J, et al. Acetazolamide-responsive exercise-induced episodic ataxia associated with a novel homozygous DARS2 mutation. Journal of medical genetics. 2011; 48(10):713-5 Epub 2011/07/14.

8. Mikhailova SV, Zakharova E, Banin AV, Demushkina AA, Petrukhin AS Clinical and molecular genetic diagnosis of leukoencephalopathy with brainstem and spinal cord involvement and lactate elevation in children. Zhurnal nevrologii i psikhiatrii imeni SS Korsakova. 2009;109(9): 16-22 Epub 2009/09/23.

9. $\mathrm{Xu} \mathrm{JG}$, Zhang JH, Chen JW. Study on the change of the content of cantharidin in Mylabris befere and after biortransfermation. Zhong Yao Cai. 2011;34(8):1180-2 Epub 2012/01/12

10. Taskin BD, Karalok ZS, Gurkas E, Aydin K, Aydogmus U, Ceylaner S, et al. Early-onset mild type leukoencephalopathy caused by a homozygous EARS2 mutation. Journal of child neurology. 2016;31(7):938-41 Epub 2016/ 02/20.

11. Moulinier L, Ripp R, Castillo G, Poch O, Sissler M. MiSynPat: an integrated knowledge base linking clinical, genetic, and structural data for diseasecausing mutations in human mitochondrial aminoacyl-tRNA synthetases. Hum Mutat. 2017:38(10):1316-24 Epub 2017/06/14

12. Brandon MC, Lott MT, Nguyen KC, Spolim S, Navathe SB, Baldi P, et al. MITOMAP: a human mitochondrial genome database--2004 update. Nucleic acids research. 2005;33(Database issue):D611-3 Epub 2004/12/21.

13. Webb BD, Wheeler PG, Hagen JJ, Cohen N, Linderman MD, Diaz GA, et al. Novel, compound heterozygous, single-nucleotide variants in MARS2 associated with developmental delay, poor growth, and sensorineural hearing loss. Hum Mutat. 2015;36(6):587-92 Epub 2015/03/11.

14. Bayat $V$, Thiffault I, Jaiswal M, Tetreault M, Donti T, Sasarman F, et al. Mutations in the mitochondrial methionyl-tRNA synthetase cause a neurodegenerative phenotype in flies and a recessive ataxia (ARSAL) in humans. PLoS biology. 2012;10(3):e1001288 Epub 2012/03/27.

15. van Berge L, Dooves S, van Berkel CG, Polder E, van der Knaap MS, Scheper GC. Leukoencephalopathy with brain stem and spinal cord involvement and lactate elevation is associated with cell-type-dependent splicing of mtAspRS mRNA. The Biochemical journal. 2012;441(3):955-62 Epub 2011/ $10 / 26$.
16. Biancheri R, Lamantea E, Severino M, Diodato D, Pedemonte M, Cassandrini $D$, et al. Expanding the clinical and magnetic resonance spectrum of leukoencephalopathy with thalamus and brainstem involvement and high lactate (LTBL) in a Patient Harboring a Novel EARS2 Mutation. JIMD reports. 2015;23:85-9 Epub 2015/04/10

17. Hausmann CD, Ibba M. Aminoacyl-tRNA synthetase complexes: molecular multitasking revealed. FEMS microbiology reviews. 2008;32(4):705-21 Epub 2008/06/05.

18. Steenweg ME, Ghezzi D, Haack T, Abbink TE, Martinelli D, van Berkel CG, et al. Leukoencephalopathy with thalamus and brainstem involvement and high lactate 'LTBL' caused by EARS2 mutations. Brain. 2012;135(Pt 5):138794 Epub 2012/04/12.

19. Lin J, Chiconelli Faria E, Da Rocha AJ, Rodrigues Masruha M, Pereira Vilanova LC, Scheper GC, et al. Leukoencephalopathy with brainstem and spinal cord involvement and normal lactate: a new mutation in the DARS2 gene. J Child Neurol. 2010;25(11):1425-8 Epub 2010/05/27.

20. van der Knaap MS, Salomons GS. Leukoencephalopathy with brain stem and spinal cord involvement and lactate elevation. In: Adam MP, Ardinger HH, Pagon RA, Wallace SE, LJH B, Stephens K, et al., editors. . Seattle (WA): GeneReviews((R)); 1993.

21. Finsterer J, Zarrouk-Mahjoub S. Phenotypic spectrum of DARS2 mutations. Journal of the neurological sciences. 2017;376:117-8 Epub 2017/04/23.

22. van Berge L, Hamilton EM, Linnankivi T, Uziel G, Steenweg ME, Isohanni P, et al. Leukoencephalopathy with brainstem and spinal cord involvement and lactate elevation: clinical and genetic characterization and target for therapy. Brain. 2014;137(Pt 4):1019-29 Epub 2014/02/26.

23. Isohanni P, Linnankivi T, Buzkova J, Lonnqvist T, Pihko H, Valanne L, et al. DARS2 mutations in mitochondrial leucoencephalopathy and multiple sclerosis. Journal of medical genetics. 2010;47(1):66-70 Epub 2009/07/14.

24. Shimojima K, Higashiguchi T, Kishimoto K, Miyatake S, Miyake N, Takanashi $J$, et al. A novel DARS2 mutation in a Japanese patient with leukoencephalopathy with brainstem and spinal cord involvement but no lactate elevation. Hum Genome Variation. 2017:4:17051 Epub 2017/11/16.

25. Yelam A, Nagarajan E, Chuquilin M, Govindarajan R. Leucoencephalopathy with brain stem and spinal cord involvement and lactate elevation: a novel mutation in the DARS2 gene. BMJ case reports. 2019;12(1). Epub 2019/01/13.

26. Kohler C, Heyer C, Hoffjan S, Stemmler S, Lucke T, Thiels C, et al. Early-onset leukoencephalopathy due to a homozygous missense mutation in the DARS2 gene. Molecular and cellular probes. 2015;29(5):319-22 Epub 2015/ 09/04.

27. Yamashita S, Miyake N, Matsumoto N, Osaka H, lai M, Aida N, et al. Neuropathology of leukoencephalopathy with brainstem and spinal cord involvement and high lactate caused by a homozygous mutation of DARS2. Brain Dev. 2013;35(4):312-6 Epub 2012/06/09.

28. Miyake N, Yamashita S, Kurosawa K, Miyatake S, Tsurusaki Y, Doi H, et al. A novel homozygous mutation of DARS2 may cause a severe LBSL variant. Clinical genetics. 2011;80(3):293-6 Epub 2011/08/06

29. van Berge L, Kevenaar J, Polder E, Gaudry A, Florentz C, Sissler M, et al. Pathogenic mutations causing LBSL affect mitochondrial aspartyl-tRNA synthetase in diverse ways. Biochem J. 2013;450(2):345-50 Epub 2012/12/12.

30. Aradjanski M, Dogan SA, Lotter S, Wang S, Hermans S, Wibom R, et al. DARS2 protects against neuroinflammation and apoptotic neuronal loss, but is dispensable for myelin producing cells. Human molecular genetics. 2017; 26(21):4181-9 Epub 2017/10/07.

31. Steenweg ME, Vanderver A, Ceulemans B, Prabhakar P, Regal L, FattalValevski A, et al. Novel infantile-onset leukoencephalopathy with high lactate level and slow improvement. Archives of neurology. 2012;69(6):71822 Epub 2012/02/09.

32. Kassem H, Wafaie A, Abdelfattah S, Farid T. Leukoencephalopathy with brainstem and spinal cord involvement and lactate elevation (LBSL): assessment of the involved white matter tracts by MRI. Eur J Radiol. 2014; 83(1):191-6 Epub 2014/02/22.

33. Steenweg ME, van Berge $L$, van Berkel CG, de Coo IF, Temple IK, Brockmann $\mathrm{K}$, et al. Early-onset LBSL: how severe does it get? Neuropediatrics. 2012; 43(6):332-8 Epub 2012/10/16.

34. Steenweg ME, Pouwels PJ, Wolf NI, van Wieringen WN, Barkhof F, van der Knaap MS. Leucoencephalopathy with brainstem and spinal cord involvement and high lactate: quantitative magnetic resonance imaging. Brain : a journal of neurology. 2011;134(Pt 11):3333-41 Epub 2011/10/19.

35. Tzoulis C, Tran GT, Gjerde IO, Aasly J, Neckelmann G, Rydland J, et al. Leukoencephalopathy with brainstem and spinal cord involvement caused 
by a novel mutation in the DARS2 gene. J Neurol. 2012;259(2):292-6 Epub 2011/07/28.

36. van der Knaap MS, van der Voorn P, Barkhof F, Van Coster R, Krageloh-Mann I, Feigenbaum A, et al. A new leukoencephalopathy with brainstem and spinal cord involvement and high lactate. Annals of neurology. 2003;53(2): 252-8 Epub 2003/01/31.

37. Linnankivi T, Lundbom $N$, Autti T, Hakkinen AM, Koillinen $H$, Kuusi $T$, et al. Five new cases of a recently described leukoencephalopathy with high brain lactate. Neurology. 2004;63(4):688-92 Epub 2004/08/25.

38. Tavora DG, Nakayama M, Gama RL, Alvim TC, Portugal D, Comerlato EA Leukoencephalopathy with brainstem and spinal cord involvement and high brain lactate: report of three Brazilian patients. Arquivos de neuropsiquiatria. 2007;65(2B):506-11 Epub 2007/08/01.

39. Tillema JM, Derks MG, Pouwels PJ, de Graaf P, van Rappard DF, Barkhof F, et al. Volumetric MRI data correlate to disease severity in metachromatic leukodystrophy. Annals of clinical and translational neurology. 2015;2(9): 932-40 Epub 2015/09/25.

40. Loes DJ, Fatemi A, Melhem ER, Gupte N, Bezman L, Moser HW, et al. Analysis of MRI patterns aids prediction of progression in X-linked adrenoleukodystrophy. Neurology. 2003;61(3):369-74 Epub 2003/08/13.

41. Yahia A, Elsayed L, Babai A, Salih MA, El-Sadig SM, Amin M, et al. Intrafamilial phenotypic heterogeneity in a Sudanese family with DARS2-related leukoencephalopathy, brainstem and spinal cord involvement and lactate elevation: a case report. BMC neurology. 2018;18(1):175 Epub 2018/10/26.

42. Labauge P, Dorboz I, Eymard-Pierre E, Dereeper O, Boespflug-Tanguy O. Clinically asymptomatic adult patient with extensive LBSL MRI pattern and DARS2 mutations. Journal of neurology. 2011;258(2):335-7 Epub 2010/09/30.

43. Schicks J, Schols L, van der Knaap MS, Synofzik M. Teaching Neurolmages: MRI guides genetics: leukoencephalopathy with brainstem and spinal cord involvement (LBSL). Neurology. 2013;80(16):e176-7 Epub 2013/04/17.

44. Finsterer J, Zarrouk MS. Epilepsy in mitochondrial disorders. Seizure. 2012; 21(5):316-21 Epub 2012/03/31

45. Finsterer J, Mahjoub SZ. Presentation of adult mitochondrial epilepsy. Seizure. 2013;22(2):119-23 Epub 2012/12/04.

46. Cheng FB, Shen PP, Zhou HW, Meng HM, Yang Y, Feng JC. Adult-onset leukoencephalopathy with brain stem and spinal cord involvement in Chinese Han population: a case report and literature review. Neurology India. 2013;61(2):161-3 Epub 2013/05/07.

47. Martikainen $\mathrm{MH}$, Ellfolk U, Majamaa K. Impaired information-processing speed and working memory in leukoencephalopathy with brainstem and spinal cord involvement and elevated lactate (LBSL) and DARS2 mutations: a report of three adult patients. Journal of neurology. 2013;260(8):2078-83 Epub 2013/05/09.

48. Novoyatleva $T$, Heinrich B, Tang $Y$, Benderska N, Butchbach ME, Lorson CL, et al. Protein phosphatase 1 binds to the RNA recognition motif of several splicing factors and regulates alternative pre-mRNA processing. Human molecular genetics. 2008;17(1):52-70 Epub 2007/10/05.

49. Moed L, Shwayder TA, Chang MW. Cantharidin revisited: a blistering defense of an ancient medicine. Archives of dermatology. 2001;137(10): 1357-60 Epub 2001/10/27.

50. Han L, Sun YJ, Pan YF, Ding H, Chen X, Zhang X. Cantharidin combined with chemotherapy for Chinese patients with metastatic colorectal cancer. Asian Pacific journal of cancer prevention : APJCP. 2014;15(24):10977-9 Epub 2015/01/22.

51. Talim B, Pyle A, Griffin H, Topaloglu H, Tokatli A, Keogh MJ, et al. Multisystem fatal infantile disease caused by a novel homozygous EARS2 mutation. Brain. 2013;136(Pt 2):e228 Epub 2012/09/26.

52. Kevelam SH, Klouwer FC, Fock JM, Salomons GS, Bugiani M, van der Knaap MS. Absent thalami caused by a homozygous EARS2 mutation: expanding disease spectrum of LTBL. Neuropediatrics. 2016;47(1):64-7 Epub 2015/12/01

53. Gungor O, Ozkaya AK, Sahin Y, Gungor G, Dilber C, Aydin K. A compound heterozygous EARS2 mutation associated with mild leukoencephalopathy with thalamus and brainstem involvement and high lactate (LTBL). Brain \& development. 2016;38(9):857-61 Epub 2016/04/28.

54. Oliveira R, Sommerville EW, Thompson K, Nunes J, Pyle A, Grazina M, et al. Lethal neonatal LTBL associated with biallelic EARS2 variants: case report and review of the reported neuroradiological features. JIMD reports. 2017; 33:61-8 Epub 2016/08/31.

55. Danhauser K, Haack TB, Alhaddad B, Melcher M, Seibt A, Strom TM, et al. EARS2 mutations cause fatal neonatal lactic acidosis, recurrent hypoglycemia and agenesis of corpus callosum. Metabolic brain disease. 2016:31(3):717-21 Epub 2016/01/19

56. Sellars EA, Balmakund T, Bosanko K, Nichols BL, Kahler SG, Zarate YA. Severe metabolic acidosis and hepatopathy due to leukoencephalopathy with thalamus and brainstem involvement and high lactate. Neuropediatrics. 2017:48(2):108-10 Epub 2016/11/23.

57. Dallabona C, Diodato D, Kevelam SH, Haack TB, Wong L, Salomons GS, et al. Novel (ovario) leukodystrophy related to AARS2 mutations. Neurology. 2014;82(23):2063-71 Epub 2014/05/09.

58. Hamatani M, Jingami N, Tsurusaki Y, Shimada S, Shimojima K, Asada-Utsugi $M$, et al. The first Japanese case of leukodystrophy with ovarian failure arising from novel compound heterozygous AARS2 mutations. Journal of human genetics. 2016;61(10):899-902 Epub 2016/10/26.

59. Szpisjak L, Zsindely N, Engelhardt JI, Vecsei L, Kovacs GG, Klivenyi P. Novel AARS2 gene mutation producing leukodystrophy: a case report. J Hum Genet. 2017;62(2):329-33 Epub 2016/10/14.

60. Taglia I, Di Donato I, Bianchi S, Cerase A, Monti L, Marconi R, et al. AARS2related ovarioleukodystrophy: clinical and neuroimaging features of three new cases. Acta neurologica Scandinavica. 2018;138(4):278-83 Epub 2018/05/12.

61. Lakshmanan R, Adams ME, Lynch DS, Kinsella JA, Phadke R, Schott JM, et al. Redefining the phenotype of ALSP and AARS2 mutation-related leukodystrophy. Neurol Genet. 2017;3(2):e135 Epub 2017/03/01.

62. Dong Q, Long L, Chang YY, Lin YJ, Liu M, Lu ZQ. An adolescence-onset male leukoencephalopathy with remarkable cerebellar atrophy and novel compound heterozygous AARS2 gene mutations: a case report. J Hum Genet. 2018;63(7):841-6 Epub 2018/04/19.

63. Peragallo JH, Keller S, van der Knaap MS, Soares BP, Shankar SP. Retinopathy and optic atrophy: expanding the phenotypic spectrum of pathogenic variants in the AARS2 gene. Ophthalmic genetics. 2018;39(1):99-102 Epub 2017/08/19.

64. Kamps R, Szklarczyk R, Theunissen TE, Hellebrekers D, Sallevelt S, Boesten IB, et al. Genetic defects in mtDNA-encoded protein translation cause pediatric, mitochondrial cardiomyopathy with early-onset brain disease. Eur J Hum Genet. 2018;26(4):537-51 Epub 2018/02/15.

65. Sommerville EW, Zhou XL, Olahova M, Jenkins J, Euro L, Konovalova S, et al. Instability of the mitochondrial alanyl-tRNA synthetase underlies fatal infantile-onset cardiomyopathy. Human molecular genetics. 2019;28(2):25868 Epub 2018/10/05.

66. Mazurova S, Magner M, Kucerova-Vidrova V, Vondrackova A, Stranecky V, Pristoupilova A, et al. Thymidine kinase 2 and alanyl-tRNA synthetase 2 deficiencies cause lethal mitochondrial cardiomyopathy: case reports and review of the literature. Cardiology in the young. 2017;27(5):936-44 Epub 2016/11/15

67. Gotz A, Tyynismaa H, Euro L, Ellonen P, Hyotylainen T, Ojala T, et al. Exome sequencing identifies mitochondrial alanyl-tRNA synthetase mutations in infantile mitochondrial cardiomyopathy. American journal of human genetics. 2011;88(5):635-42 Epub 2011/05/10.

68. Haas RH, Parikh S, Falk MJ, Saneto RP, Wolf NI, Darin N, et al. The in-depth evaluation of suspected mitochondrial disease. Mol Genet Metab. 2008; 94(1):16-37 Epub 2008/02/05.

69. Antonellis A, Green ED. The role of aminoacyl-tRNA synthetases in genetic diseases. Annu Rev Genomics Hum Genet. 2008;9:87-107 Epub 2008/09/05.

70. Brown MV, Reader JS, Tzima E. Mammalian aminoacyl-tRNA synthetases: cell signaling functions of the protein translation machinery. Vasc Pharmacol. 2010:52(1-2):21-6 Epub 2009/12/08.

71. Bonnefond L, Fender A, Rudinger-Thirion J, Giege R, Florentz C, Sissler M. Toward the full set of human mitochondrial aminoacyl-tRNA synthetases: characterization of AspRS and TyrRS. Biochemistry. 2005;44(12):4805-16 Epub 2005/03/23.

72. Guo M, Schimmel P, Yang XL. Functional expansion of human tRNA synthetases achieved by structural inventions. FEBS letters. 2010;584(2):43442 Epub 2009/11/26.

73. Kim S, You S, Hwang D. Aminoacyl-tRNA synthetases and tumorigenesis: more than housekeeping. Nature reviews Cancer. 2011;11(10):708-18 Epub 2011/09/24

74. Wang $M$, Sips $P$, Khin E, Rotival M, Sun $X$, Ahmed $R$, et al. Wars2 is a determinant of angiogenesis. Nat Commun. 2016;7:12061 Epub 2016/07/09.

75. Agnew T, Goldsworthy M, Aguilar C, Morgan A, Simon M, Hilton H, et al. A Wars2 mutant mouse model displays OXPHOS deficiencies and activation of tissue-specific stress response pathways. Cell Rep. 2018;25(12):3315-28 e6. Epub 2018/12/20. 
76. Dogan SA, Pujol C, Maiti P, Kukat A, Wang S, Hermans S, et al. Tissue-specific loss of DARS2 activates stress responses independently of respiratory chain deficiency in the heart. Cell metabolism. 2014;19(3):458-69 Epub 2014/03/13.

77. Schiffmann R, Fogli A, van der Knaap MS, Boespflug-Tanguy O. Childhood ataxia with central nervous system hypomyelination/Vanishing White Matter. In: Adam MP, Ardinger HH, Pagon RA, Wallace SE, LH B, Stephens K, et al., editors. . Seattle (WA): GeneReviews((R)); 1993.

78. van der Knaap MS, Barth PG, Gabreels FJ, Franzoni E, Begeer JH, Stroink H, et al. A new leukoencephalopathy with vanishing white matter. Neurology. 1997;48(4):845-55 Epub 1997/04/01.

79. Leegwater PA, Vermeulen G, Konst AA, Naidu S, Mulders J, Visser A, et al. Subunits of the translation initiation factor elF2B are mutant in leukoencephalopathy with vanishing white matter. Nature genetics. 2001; 29(4):383-8 Epub 2001/11/13.

80. Wortham NC, Proud CG. Biochemical effects of mutations in the gene encoding the alpha subunit of eukaryotic initiation factor (eIF) $2 B$ associated with Vanishing White Matter disease. BMC Med Genet. 2015;16:64 Epub 2015/08/20

81. Yang $W$, Hinnebusch AG. Identification of a regulatory subcomplex in the guanine nucleotide exchange factor elF2B that mediates inhibition by phosphorylated elF2. Molecular and cellular biology. 1996;16(11):6603-16 Epub 1996/11/01.

82. Hinnebusch AG, Lorsch JR. The mechanism of eukaryotic translation initiation: new insights and challenges. Cold Spring Harbor perspectives in biology. 2012;4(10). Epub 2012/07/21.

83. Sekine Y, Zyryanova A, Crespillo-Casado A, Fischer PM, Harding HP, Ron D. Stress responses. Mutations in a translation initiation factor identify the target of a memory-enhancing compound. Science. 2015;348(6238):1027-30 Epub 2015/04/11.

84. Sidrauski C, Tsai JC, Kampmann M, Hearn BR, Vedantham P, Jaishankar P, et al. Pharmacological dimerization and activation of the exchange factor elF2B antagonizes the integrated stress response. elife. 2015;4:e07314 Epub 2015/04/16.

85. van Kollenburg B, Thomas AA, Vermeulen G, Bertrand GA, van Berkel CG, Pronk $\mathrm{JC}$, et al. Regulation of protein synthesis in lymphoblasts from vanishing white matter patients. Neurobiol Dis. 2006;21(3):496-504 Epub 2005/09/28.

86. Liu R, van der Lei HD, Wang X, Wortham NC, Tang H, van Berkel CG, et al. Severity of vanishing white matter disease does not correlate with deficits in elF2B activity or the integrity of elF2B complexes. Hum Mutat. 2011;32(9): 1036-45 Epub 2011/05/12.

87. Fogli A, Schiffmann R, Hugendubler L, Combes P, Bertini E, Rodriguez D, et al. Decreased guanine nucleotide exchange factor activity in elF2Bmutated patients. European journal of human genetics : EJHG. 2004;12(7): 561-6 Epub 2004/04/01.

88. Li W, Wang X, Van Der Knaap MS, Proud CG. Mutations linked to leukoencephalopathy with vanishing white matter impair the function of the eukaryotic initiation factor 2B complex in diverse ways. Mol Cell Biol. 2004;24(8):3295-306 Epub 2004/04/03.

89. Wong YL, LeBon L, Edalji R, Lim HB, Sun C, Sidrauski C. The small molecule ISRIB rescues the stability and activity of Vanishing White Matter Disease elF2B mutant complexes. eLife. 2018;7 Epub 2018/03/01.

90. Bugiani M, Boor I, Powers JM, Scheper GC, van der Knaap MS Leukoencephalopathy with vanishing white matter: a review. Journal of neuropathology and experimental neurology. 2010;69(10):987-96 Epub 2010/09/15

91. Dooves S, Bugiani M, Postma NL, Polder E, Land N, Horan ST, et al. Astrocytes are central in the pathomechanisms of vanishing white matter. J Clin Investig. 2016;126(4):1512-24 Epub 2016/03/15.

92. Bugiani M, Boor I, van Kollenburg B, Postma N, Polder E, van Berkel C, et al. Defective glial maturation in vanishing white matter disease. Journal of neuropathology and experimental neurology. 2011;70(1):69-82 Epub 2010/ $12 / 16$

93. Wong YL, LeBon L, Basso AM, Kohlhaas KL, Nikkel AL, Robb HM, et al. elF2B activator prevents neurological defects caused by a chronic integrated stress response. eLife. 2019;8 Epub 2019/01/10.

\section{Publisher's Note}

Springer Nature remains neutral with regard to jurisdictional claims in published maps and institutional affiliations.

\section{Ready to submit your research? Choose BMC and benefit from:}

- fast, convenient online submission

- thorough peer review by experienced researchers in your field

- rapid publication on acceptance

- support for research data, including large and complex data types

- gold Open Access which fosters wider collaboration and increased citations

- maximum visibility for your research: over $100 \mathrm{M}$ website views per year

At BMC, research is always in progress.

Learn more biomedcentral.com/submissions 